


\section{About IJMA [last updated October, $\left.1^{\text {st }}, 2021\right]$}

$\checkmark$ International Journal of Medical Arts is the Official Journal of the Damietta Faculty of Medicine, AlAzhar University, Egypt

$\checkmark$ It is an International, Open Access, Double-blind, Peer-reviewed Journal

$\checkmark$ Published four times a year

$\checkmark$ The First Issue was published in July 2019

$\checkmark$ Published under the following license: Creative Commons Attribution-ShareAlike 4.0 International Public License (CC BY-SA 4.0). It had updated from the Creative Commons license [CC BY] in volume 2, Issue 4, October 2020 About IJMA

$\checkmark$ The Egyptian Knowledge Bank hosts the web site of IJMA

$\checkmark$ The Egyptian Knowledge Bank supports IJMA

$\checkmark$ IJMA follows the regulations of the International Committee of Medical Journal Editors

$\checkmark$ IJMA is indexed in the "Directory of Open Access Journals" [15 January 2021].

$\checkmark$ IJMA is indexed in J-Gate [29-6-2021]

$\checkmark$ IJMA is a member of the International Society of Managing and Technical Editors

$\checkmark$ Listed in "Index Copernicus", "Publons", "Academic resource index [ResearchBib]" "Electronics journal library", "Eurasian Scientific Journal Index", "WorldCat" Superstar Journal Database, and "Citefactor"

$\checkmark$ IJMA introduced to the search engine [BASE] through DOAJ

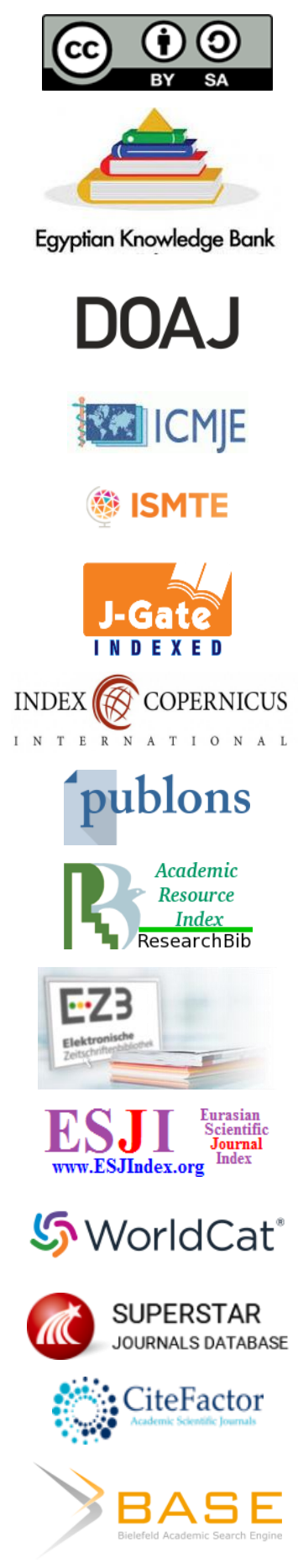




Available online at Journal Website
https://ijma.journals.ekb.eg/
Main subject [Obstetrics and Gynecology]

Original Article

\title{
Three Dimensional Power Doppler Ultrasound in Assessment of Placental Volume and Blood Flow and its Correlation with Severity of Pre-Eclampsia
}

\author{
Mohamed Ahmed Alsharnoby [1], Mohamed Mohamed Gebreel [1], Ahmed Mohamed Alsheikh [1]
}

${ }^{1}$ Department of Obstetrics and Gynecology, Faculty of Medicine, Al-Azhar University, Egypt

Corresponding author: Mohamed Ahmed Alsharnoby

Email: msharnoby8880@gmail.com

Submission date: July 1, 2021; Acceptance date: October 6, 2021

DOI: $10.21608 / \mid J M A .2021 .83424 .1334$

DOAJ

\section{ABSTRACT}

Background: Pre-eclampsia [PE] is a main reason for maternal and perinatal morbidities and mortalities. Three-dimensional power Doppler ultrasound [3DPD-US] methods nowadays give a noninvasive way of evaluating placental vascularization, flowing and vascularization-flowing indices. The specially designed VOCAL software, used in this technique, can calculate special indices and virtually reconstruct vascular tree within the given tissue volume.

Aim of the work: To evaluate the use of three-dimensional power Doppler [3DPD] ultrasound [US] in assessment of placental size and blood flow and its correlation with severity of pre-eclampsia.

Patients and Methods: This is a cross-sectional study which included 100 pregnant females with pre-eclampsia who had admitted to the Obstetrics and Gynecology Department of Bab-Alsheiria University Hospitals at the last antenatal care visit before delivery. The sample size was further allocated into 2 groups, each containing 50 cases, according to the severity of preeclampsia: the severe group and the mild group.

Results: There was a significant decrease in the placental volumes and blood flows among the studied groups. All three indices measuring vascularization index [VI], flow index [FI] and vascularization flow index [VFI] were revealed to be significantly higher in the mild group in comparison with the severe group.

Conclusion: 3DPD-US can give novel insights into valuation of placental volumes and blood flow and its correlation with severity of preeclampsia.

\footnotetext{
Keywords: Three dimensional power Doppler ultrasound; mild; severe; Preeclampsia.

This is an open-access article registered under the Creative Commons, ShareAlike 4.0 International license [CC BY-SA 4.0] [https://creativecommons.org/licenses/by-sa/4.0/legalcode.
}

Citation: Alsharnoby MA, Gebreel MM, Alsheikh AM. Three Dimensional Power Doppler Ultrasound in Assessment of Placental Volume and Blood Flow and its Correlation with Severity of Pre-Eclampsia. IJMA 2021; 3 [4] October-December: 1874-1878 [DOI: 10.21608/IJMA.2021.83424.1334].

* Main subject and any subcategories have been classified according to the research topic 


\section{INTRODUCTION}

Preeclampsia is the main cause of maternal and perinatal morbidities and mortalities described as the incidence of high blood pressure and substantial proteinuria in formerly healthy women on or after the 20th-wk of pregnancy. It happens in around $2-8 \%$ of all pregnant women $[1]$.

Preeclampsia is defined according to ACOG guidelines as permanent BP $140-\mathrm{mmHg}$ systolic and/or diastolic $90-$ $\mathrm{mmHg}$ happening after the 20th-wk of pregnancy and proteinuria $>0.3-\mathrm{g} /$ day or entire protein/creatinine ratio $>0.3$ [or 1+ proteinuria on urine dip stick examination on at least 2 occasions] ${ }^{[2]}$.

Three-dimensional power Doppler ultrasound [3DPD-US] methods nowadays give a noninvasive way of evaluating placental vascularization and flow indices; vascularization, flowing and vascularization-flowing indices. 3DPD-US may describe interior placental vessel features like densities of vessels, branching, caliber variations, and tortuousness [3].

3D-US can give upgraded visualizations of embryonic anatomy in comparison to conventional two-dimensional [2D] US scanning. Subsequently, the introduction of 3DUS could simplify the new evaluation of the placenta, like surfacerendering scanning and size measurements. With the new developments in 3DPD-US, in addition to quantitative 3DPD histogram analysis, qualitative and quantitative evaluations of the vascularization and blood flow of the placenta have been possible ${ }^{[3]}$.

The combinations of power and color Doppler sonography measures blood movements in very small vessels and allows calculations of their impact on the total perfusion of a given placenta size. These indices are computed via built-in algorithms in the VOCAL [Virtual Organ Computer-aided Analysis] package [3].

\section{AIM OF THE WORK}

To detect differences in placental condition regarding volume, vasculature, and blood flow between Mild and Severe Preeclampsia using 3DPD-US.

\section{PATIENTS AND METHODS}

This is a cross-sectional research which included 100 pregnant females who had presented and admitted to the Obstetrics and Gynecology Department of Bab Alseheiria University Hospitals at the last antenatal care visit before delivery. The study was done over a period of 6 months starting from Jan 2021 to June 2021. The sample size was further allocated into 2 groups, every one containing 50 cases, according to the severity of preeclampsia: severe group and mild group.

Diagnostic criteria for mild preeclampsia: Preeclampsia was identified as high BP [140/90 or more] on at least 2 occasions, 6 hours apart, first recognized in this pregnancy, and detected after 20 weeks of gestation, together with proteinuria [ $>300 \mathrm{mg}$ in $24 \mathrm{hr}$ urinary proteins, or albumin +1 or higher in complete urine analysis] [4].

Criteria of severity of preeclampsia: Severe preeclampsia was defined if any of the following severe features are present: systolic BP $>160 \mathrm{mmHg}$ or diastolic BP $>110$ $\mathrm{mmHg}$, while the patient at bed rest, on two occasions, at least 4 hours apart [unless anti-hypertensive therapy is initiated before this time]. Other features of severity include: thrombocytopenia [platelet count $<100,000$ ], abnormal liver function [elevated blood levels of liver transaminases to twice the normal concentration, severe persistent right upper quadrant or epigastric pain unresponsive to medication and not explained by alternative diagnoses, or both], new growth of renal insufficiency [elevated serum creatinine greater than $1.1 \mathrm{mg} / \mathrm{dl}$, or doubling of serum creatinine in the nonexistence of other reversible causes], new-onset cerebral or visual abnormalities, or pulmonary edema ${ }^{[4]}$.

Inclusion criteria: Pregnant women in the 3rd trimester [> 26wks], singleton pregnancy with normal fetal morphology and diagnosed with pre-eclampsia were included.

Exclusion criteria: Fetal chromosomal anomalies and deformities, placental irregularities [placental bipartite or velamentous insertion], placenta previa and abnormally invasive placenta, umbilical anomalies [single umbilical artery, vasa previa], other complications accompanying with gestation [gestational diabetes, intra-hepatic cholestasis and anemia], systemic vascular or auto-immune diseases [systemic lupus erythematosus and rheumatoid arthritis], ruptures of the amniotic membranes, women taking vasoactive medications and self-reported drug, alcohol, or nicotine abuse.

The study groups were evaluated for full history of obstetric and gynecological history. Physical examination included vital signs and abdominal examination for determination of fetal lie, position and size. Laboratory investigations included complete blood picture with platelet count, liver enzymes, serum creatinine levels and 24-hour urine proteins. 
Verbal and written informed consents were taken before the start of the study. The presented study was approved by the Research and Ethical committee, Faculty of Medicine-AlAzhar University.

\section{Statistical analysis}

Data were fed to the computer and analyzed using IBM SPSS software package version 20.0. [Armonk, NY: IBM Corp]. Qualitative data were described using number and percent. The Kolmogorov-Smirnov test was used to verify the normality of distribution. Quantitative data were described using range [minimum and maximum], mean and standard deviation. Chi-square test was used for categorical variables, to compare between different groups, Student ttest was used for normally quantitative variables, to compare between two studied groups, and Mann Whitney test was used for abnormally quantitative variables, to compare between two studied groups. Significance of the obtained results was judged at the $5 \%$ level.
Patients were classified into 2 groups; group (A): included 50 patients with mild preeclampsia, and group (B): included 50 patients with severe preeclampsia.

Patients with severe preeclampsia had significantly lower gestational age $[P=0.034]$, higher systolic blood pressure $[170.70 \pm 5.697$ vs. $150.50 \pm 5.825 ; \mathrm{P}=0.037]$. No other significant difference regarding maternal age, weight height, $\mathrm{BMl}$ and diastolic blood pressure [Table 1].

There was significant elevation of ALT, creatinine and $24 \mathrm{~h}$ urinary proteins among patients with severe preeclampsia [Table 2].

On Comparison between two groups as regard to patients' vascularization index, In the Flow index, vascularization flow index; there was statically significant difference among the studied groups [Table 3].

Table [1]: Comparing between both groups regarding demographic and clinical characteristics

\begin{tabular}{lccccc} 
& & Group $[\mathrm{A}][\mathbf{n}=5 \mathbf{5 0}$ & Group [B] [n=50] & Test & P-Value \\
Gestational age & Min-Max & $32-39$ & $29-38$ & $\mathrm{u}=633.00$ & $\mathbf{0 . 0 3 4}$ \\
& Mean \pm SD & $36.40 \pm 3.541$ & $34.48 \pm 3.683$ & & \\
Maternal age & Min-Max & $21-38$ & $22-40$ & $\mathrm{u}=1014.50$ & 0.103 \\
& Mean \pm SD & $26.12 \pm 4.003$ & $28.08 \pm 3.440$ & & \\
Weight & Min-Max & $62-95$ & $61-100$ & $\mathrm{u}=1245.00$ & 0.975 \\
& Mean \pm SD & $79.22 \pm 10.432$ & $79.34 \pm 10.205$ & & \\
Height & Min-Max & $153-180$ & $152-181$ & $\mathrm{u}=1116.50$ & 0.357 \\
& Mean \pm SD & $167.42 \pm 8.355$ & $165.82 \pm 8.665$ & & \\
Body mass & Min-Max & $19.79-37.21$ & $20.52-38.22$ & $\mathrm{t}=0.662$ & 0.509 \\
index [BMI] & Mean \pm SD & $28.45 \pm 4.576$ & $29.06 \pm 4.614$ & & \\
Systolic Blood & Min-Max & $140-160$ & $150-200$ & $\mathrm{u}=789.00$ & $\mathbf{0} .037$ \\
Pressure & Mean \pm SD & $150.50 \pm 5.825$ & $170.70 \pm 5.697$ & & \\
Diastolic Blood & Min-Max & $90-100$ & $90-130$ & $\mathrm{u}=1038.00$ & 0.075 \\
Pressure & Mean \pm SD & $96.30 \pm 3.164$ & $110.30 \pm 3.066$ & & \\
\hline
\end{tabular}

u: Mann-Whitney test; t: Student T-test

Table [2]: Comparing between both groups regarding laboratory data

\begin{tabular}{lccccc}
\hline & & Group [A] [n=50] & Group [B] [n=50] & Test & P value \\
\hline AST & Min-Max & $25-65$ & $72-360$ & $\mathrm{t}=0.106$ & 0.116 \\
& Mean \pm SD & $45.84 \pm 11.767$ & $110.58 \pm 12.738$ & & \\
ALT & Min-Max & $32-51$ & $63-489$ & $\mathrm{u}=941.50$ & $\mathbf{0 . 0 3 3 ^ { * }}$ \\
& Mean \pm SD & $41.10 \pm 5.853$ & $194.58 \pm 5.485$ & & \\
Creatinine & Min-Max & $0.80-1.30$ & $0.70-3$ & $\mathrm{u}=1137.00$ & $\mathbf{0 . 0 4 3}$ \\
& Mean \pm SD & $1.22 \pm 0.57$ & $1.36 \pm 0.328$ & & \\
24 hours & Min-Max & $305-880$ & $340-6000$ & $\mathrm{u}=1130.50$ & $\mathbf{0 . 0 3 9}$ \\
proteins & Mean \pm SD & $422.40 \pm 56.365$ & $1952.32 \pm 54.586$ & & \\
\hline
\end{tabular}

u: Mann-Whitney test; t: Student T-test 
Table [3]: Comparison between the two groups as regard to patients' 3P Doppler Ultrasound parameters

\begin{tabular}{|c|c|c|c|c|c|}
\hline & & Group [A] [n=50] & Group [B] $[n=50]$ & Test & P-Value \\
\hline Placental volume & $\begin{array}{c}\text { Min-Max } \\
\text { Mean } \pm \text { SD }\end{array}$ & $\begin{array}{c}180-540 \\
268.88 \pm 82.923\end{array}$ & $\begin{array}{c}116-313 \\
198.56 \pm 45.166\end{array}$ & $\mathrm{u}=569$. & $<0.001^{*}$ \\
\hline $\begin{array}{l}\text { Vascularization } \\
\text { index [VI] }\end{array}$ & $\begin{array}{c}\text { Min-Max } \\
\text { Mean } \pm \text { SD }\end{array}$ & $\begin{array}{c}8-31 \\
16.96 \pm 5.57\end{array}$ & $\begin{array}{c}1-13 \\
8.52 \pm 2.71\end{array}$ & $u=144.5$ & $<0.001^{*}$ \\
\hline Flow Index [FI] & $\begin{array}{c}\text { Min-Max } \\
\text { Mean } \pm \text { SD }\end{array}$ & $\begin{array}{c}20-54 \\
36.14 \pm 7.401\end{array}$ & $\begin{array}{c}7-46 \\
26.04 \pm 8.26\end{array}$ & $t=6.438$ & $<0.001^{*}$ \\
\hline $\begin{array}{l}\text { Vascularization } \\
\text { flow index [VFI] }\end{array}$ & $\begin{array}{c}\text { Min-Max } \\
\text { Mean } \pm \text { SD }\end{array}$ & $\begin{array}{c}2-8 \\
4.48 \pm 1.47\end{array}$ & $\begin{array}{c}1-4 \\
2.68 \pm 0.74\end{array}$ & $u=357$ & $<0.001^{*}$ \\
\hline
\end{tabular}

\section{DISCUSSION}

Quantitative 3DPD analysis was utilized to evaluate placental perfusions and vascularization indices that mirror both utero-placental and feto-placental blood perfusions. Direct investigations of the perfusion of in vivo placentae have been feasible. Even every small blood motion within the studied size may be recorded by a mixture of power and color Doppler sonography reflected by these indices [3].

The three indices or parameters assessing placental perfusion and vascularization are the vascularization index [VI], which is the determination of the percentage of vascularized tissues. The Vascularization flow index [VFI] measures the relative amount of moving blood in the sampled tissues. FI [Flow index] measures the amplitude of the blood movements in the sampled placental site ${ }^{[3]}$.

De Paula et al. [6] demonstrated that all placental vascular indices assessed via 3DPD presented a persistent distribution during pregnancy in spite of the rise in placenta volume in accordance to pregnancy age. In the present study, we revealed a significant association [P-value 0.05] between gestational age and severity of preeclampsia and placental volume. In another study, by Moran et al. [7], there was no correlation between size and gestational age among pre-eclampsia patients. In the same study, VI and VFI aren't impacted by pregnancy, but $\mathrm{FI}$ was detected to rise with pregnancy age. All 3 indices were less than standard values in-between 24-and 30-wks. This is in accordance with the present work as the three indices were found to be significantly lower than the reference limit, although pregnancy was in the third trimester in both non-severe and severe groups. This placenta volume could only be a prognosticator of the severity of preeclampsia.

In contrast to our studies, Rizzo et al. ${ }^{[8]}$ performed prospective observational research on 32-pregnancies at the 1 st trimester of gestation to evaluate placental volume. They found a non-significant change in the placenta volume when compared to the reference limit. A change in the number of preeclampsia patients in the studied groups could play a role in the different results.
The present work was performed to determine the placenta vascularization in the third trimester of gestation and its connection with pre-eclampsia severity. All three indices measures $\mathrm{VI}, \mathrm{FI}$ and $\mathrm{VFI}$ were revealed to be high significantly in the non-severe group in comparison with the severe group.

As in the present study, Yuan et al. ${ }^{[0]}$ stated that all 3DPD indices had a significant relationship with gestation age, and $\mathrm{FI}, \mathrm{VI}$, and $\mathrm{VFI}$ of the placenta were significantly lower in the severe preeclampsia group in comparison with the ordinary group. Furthermore, in accordance with our results, they stated that there was a significant decrease in $\mathrm{VI}$ and VFI vascular indices comparing the non-severe and severe groups of preeclampsia. In comparison with normotensive cases, cases with severe pre-eclampsia had a significant decrease in placenta VI \& VFI. There is marked similarity with the results of the present work as comparison of $\mathrm{VI}$ in the non-severe group to normal reference value showed a non-significant decrease in our work.

Thus, according to Yuan et al. [9], intra-placental vascularization was worse in females with severe preeclampsia, while damage to placenta vessels may be relatively mild in non-severe preeclampsia.

The findings of the present work were in agreement with Chen et al. [3], who stated that all three indices were significantly lower in severe pre-eclamptic placenta in comparison with control and that the severity of preeclampsia couldn't be expected by vascular indices.

Mercé et al. ${ }^{[10]}$ found an increase in VI, FI and VFI with a positive correlation with gestational age, but this author identified only a portion of the placenta with the maximum density of vessels, a technique called vascular placental biopsy.

These results are in contrast to Guiot et al. [11], who found a decrease in VI, FI and VFI. This could be due to the fact that they calculated vascular indices in five constant regions of the placenta. 
In contrast to the present study, the results of Suranyi et al. [12], reported lower VI in gestations complicated by preeclampsia in comparison with controls, though the change was non-significant.

Our objective was to examine volume and placental vascularization in both non-severe and severe groups of preeclampsia in the third trimester. A decrease in measured parameters in both groups was seen, which can help in detection of preeclampsia. Therefore, we may decide about managing and monitoring strategies.

3DPD sonography can give new visions into placenta pathophysiology. Additional research is desired to determine its accuracy when utilized in clinical practices as a supernumerary or an assistant to umbilical artery Doppler. Also, possible correlation with clinical biomarkers during preeclampsia such as soluble fms-like tyrosine kinase 1 [sFI/t-1] or placenta growing factor [PIGF] could help in management. In spite of multiple publications and journal submissions using 3DPD, the consistency and reproducibility of parameters are still suspected. Fixed reference values for prognosis and management are still lacking.

\section{CONCLUSION}

3DPD-US can give novel insights into evaluation of placental volumes and blood flow and its correlation with severity of preeclampsia. Additional research is desired to confirm its accuracy when utilized in clinical practices. In this study, a comparison between mild and severe pre-eclamptic patients as regards placental volume showed that there was a significant decrease in the placenta size among the studied groups. We revealed a non-significant association [P-value $>0.05$ ] between gestational age and the volume of the placenta regarding the severity of preeclampsia. All three indices measuring $\mathrm{VI}, \mathrm{FI}$ and $\mathrm{VFI}$ were revealed to be significantly higher in the mild group in comparison with the severe group.

\section{Financial and Non-financial Relationships and Activities of Interest}

None

\section{REFERENCES}

1. Rana S, Lemoine E, Granger JP, Karumanchi SA. Preeclampsia: Pathophysiology, Challenges, and Perspectives. Circ Res. 2019 Mar 29;124[7]:1094-1112. DOI: 10.1161/CIRCRESAHA.118.313276.

2. Croke L. Gestational Hypertension and Preeclampsia: A Practice Bulletin from ACOG. Am Fam Physician. 2019 Nov 15;100[10]:649-650. PMID: 31730305.
3. Chen SJ, Chen CP, Sun FJ, Chen CY. Comparison of Placental Three-Dimensional Power Doppler Vascular Indices and Placental Volume in Pregnancies with Small for Gestational Age Neonates. J Clin Med. 2019 Oct 11;8[10]:1651. DOI: 10.3390/jcm8101651.

4. Wisner K. Gestational Hypertension and Preeclampsia. MCN Am J Matern Child Nurs. 2019 May/Jun;44[3]:170. DOl: 10.1097/NMC. 0000000000000523.

5. Kirkpatrick LA. A Simple Guide to IBM SPSS Statistics-Version 23.0: Cengage Learning; 2015.

6. de Paula CF, Ruano R, Campos JA, Zugaib M. Quantitative analysis of placental vasculature by three-dimensional power Doppler ultrasonography in normal pregnancies from 12 to 40 weeks of gestation. Placenta. 2009 Feb;30[2]:142-8. DOl: 10.1016/j.placenta.2008.11.010.

7. Moran MC, Mulcahy C, Zombori G, Ryan J, Downey P, McAuliffe FM. Placental volume, vasculature and calcification in pregnancies complicated by pre-eclampsia and intra-uterine growth restriction. Eur J Obstet Gynecol Reprod Biol. 2015 Dec;195:12-7. DOI: 10.1016/j.ejogrb.2015.07.023.

8. Rizzo G, Silvestri E, Capponi A, Servadei F, Pietrolucci ME, Capece A, Pisa R, Arduini D. Histomorphometric characteristics of first trimester chorionic villi in pregnancies with low serum pregnancy-associated plasma protein-A levels: relationship with placental three-dimensional power doppler ultrasonographic vascularization. J Matern Fetal Neonatal Med. 2011;24[2]:253-7. DOI: 10.3109/14767058.2010.482627.

9. Yuan $T$, Zhang $T$, Han Z. Placental vascularization alterations in hypertensive disorders complicating pregnancy [HDCP] and small for gestational age with HDCP using three-dimensional power doppler in a prospective case control study. BMC Pregnancy Childbirth. 2015 Oct 5;15:240. DOI: 10.1186/ s12884-015-0666-1.

10. Merce LT, Barco MJ, Bau S, Kupesic S, Kurjak A. Assessment of placental vascularization by three-dimensional power Doppler "vascular biopsy" in normal pregnancies. Croat Med J. 2005 Oct;46[5]:765-71. PMID: 16158469.

11. Bahado-Singh RO, Syngelaki A, Akolekar R, Mandal R, Bjondahl TC, Han B, et al. Validation of metabolomic models for prediction of early-onset preeclampsia. Am J Obstet Gynecol. 2015 Oct;213[4]:530.e1-530.e10. DOI: 10.1016/j. ajog.2015.06.044.

12. Surányi A, Altorjay Á, Kaiser L, Nyári T, Németh G. Evaluation of placental vascularization by three-dimensional ultrasound examination in second and third trimester of pregnancies complicated by chronic hypertension, gestational hypertension or pre-eclampsia. Pregnancy Hypertens. 2017 Apr;8:51-59. DOI: 10.1016/j.preghy.2017.03.004. 


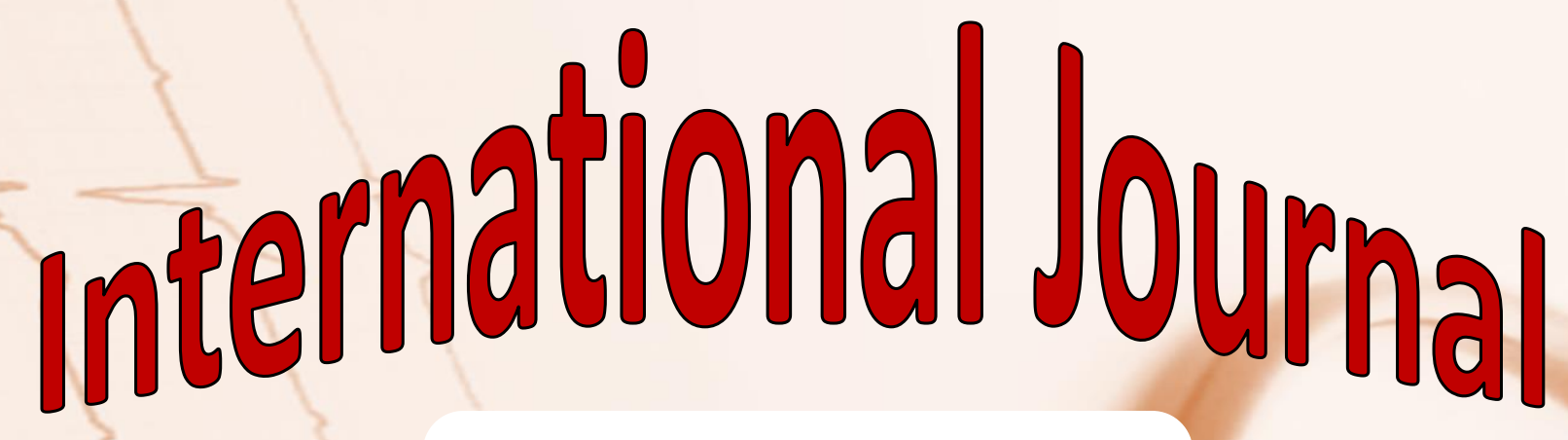

https://ijma.journals.ekb.eg/ Print ISSN: 2636-4174 Online ISSN: 2682-3780

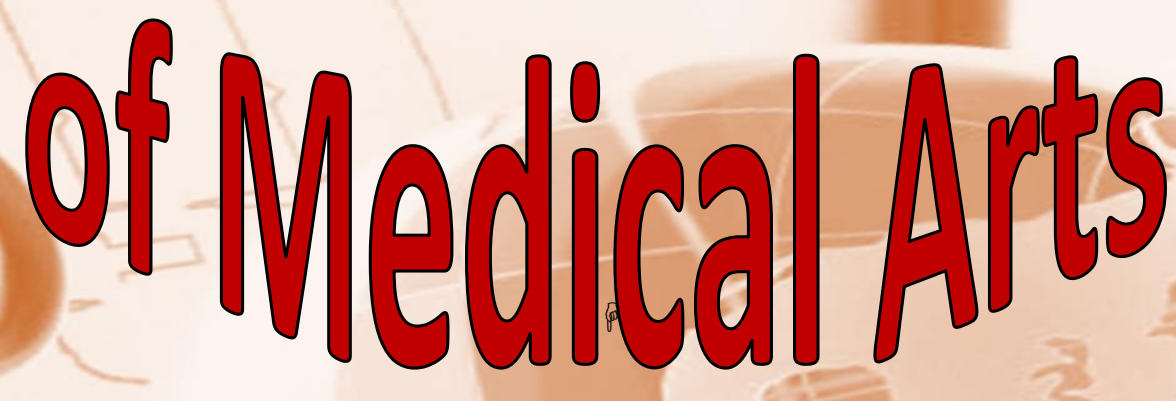

